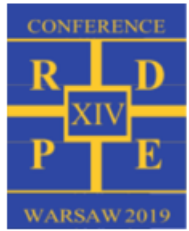

\title{
Sizing of biomass-fired ORC cogeneration unit within coal-fired municipal heating plant back fitting project
}

\author{
Jacek K alina ${ }^{1, *}$, Mateusz Świerzewski ${ }^{1}$ \\ ${ }^{1}$ Silesian University of Technology, A kademicka 2A, 44-100 Gliwice, jacek.kalina@ polsl.pl, Poland
}

\begin{abstract}
The problem discussed in this paper is optimal sizing of biomass-fired ORC cogeneration units into existing coal-fired district heating plants under given site-specific technical, economic and ecological constraints. In this paper the municipal heating plant in Krosno (Poland) is taken into account as the reference case. Basing on the operational experiences from this unit an optimisation study has been performed in order to examine the influence of current economic and legal conditions on the optimal design characteristics of the plant. Different electricity, biomass and coal prices are taken into account as well as the influence of the EUA (European Emission Allowance) price is examined. There are taken into account thermal energy storage and sale of electricity on balancing market. It has been found that in the studied case the implementation of hot water storage tank moves the optimal electric power output slightly towards higher values. On the other hand only a small improvement of financial performance has been gained. The results reveal importance of the optimisation of design parameters as well as the dependence of the plant's size and structure on local economic conditions.
\end{abstract}

\section{Introduction}

A possible way for deployment of Renewable Energy Sources (RES) technologies into the energy market is modernisation and retrofitting of existing fossil-fuelfired production facilities [1]. In the case of biomass, there have been usually initiated cogeneration projects in locations where a heat market had existed. Therefore, most of biomass-fired ORC systems have been installed in district heating systems [2]. The biomass-fired ORC modules are usually being added to existing fossil-fuelfired heating plants within backfitting projects focused on using locally available feedstock, making profits out of electricity generation and $\mathrm{CO}_{2}$ emission reduction. Such projects result in change of a given heating plant into a dual-fuel cogeneration plant (CHP). The critical issue of a project of this type is optimal selection of the biomass-fired block size and its integration with the existing heat only boilers. The design task also includes elaboration of operational strategy and design of control algorithms as the system will run under variable load and price conditions. Current experience shows that cogeneration modules have been traditionally sized for either base or medium heating load of district heating network [3, 4]. However, for best effects the optimisation task must be properly formulated under site-specific heating load profile, economic (including financial support mechanism) and legal conditions [5], including different strategies to sell electric energy generated in cogeneration.

There have been presented in the literature several studies on optimisation of ORC cogeneration systems [4 - 9]. The critical problem of such task is selection of proper objective function and constraints. In industrial practice optimization is usually carried out using an economic objective function, expressed by local financial effect [10-11].

In this work, there is presented simulation based optimisation of ORC system size and technological structure within backfitting projects of district heating plants. The optimisation task has been solved by searching the area of allowable solutions and therefore impact of key design variables on objective function has been depicted. The proposed methodology has been based on operational experiences of a real case. The municipal heating plant in Krosno (Poland) has been taken into account as the reference system. In 2013 there was commissioned biomass biomass-fired cogeneration system with the Turboden T14 CHP SPLIT unit of 1255 $\mathrm{kW}$ net electric power. The optimization study has been performed in order to examine the impact of current economic and legal conditions on the optimal design characteristics of the ORC system. The main decision variables have been power output of the ORC unit, presence of thermal energy storage tank (TES) and its volume. Different electricity, biomass and coal prices are taken into account as well as the influence of the EUA (European Emission Allowance) price is examined. The results reveal importance of the optimisation of design parameters as well as the dependence of the plant's size and structure on local economic conditions.

\section{Reference system}

In the city of Krosno the biomass-fired CHP block has been added to existing coal-fired heating plant. At present, the technological system consists of two subsystems, namely the coal-fired heat-only boiler (HOB) subsystem and the biomass-fired CHP 
subsystem. Schematic diagram of the integrated plant has been depicted in Fig. 1. Duration curves of heating load, network water temperature and flow have been shown in Fig. 2 and 3. The peak heating load of the system is around $30 \mathrm{MW}$ and the maximum grid forward water temperature is around $125^{\circ} \mathrm{C}$.

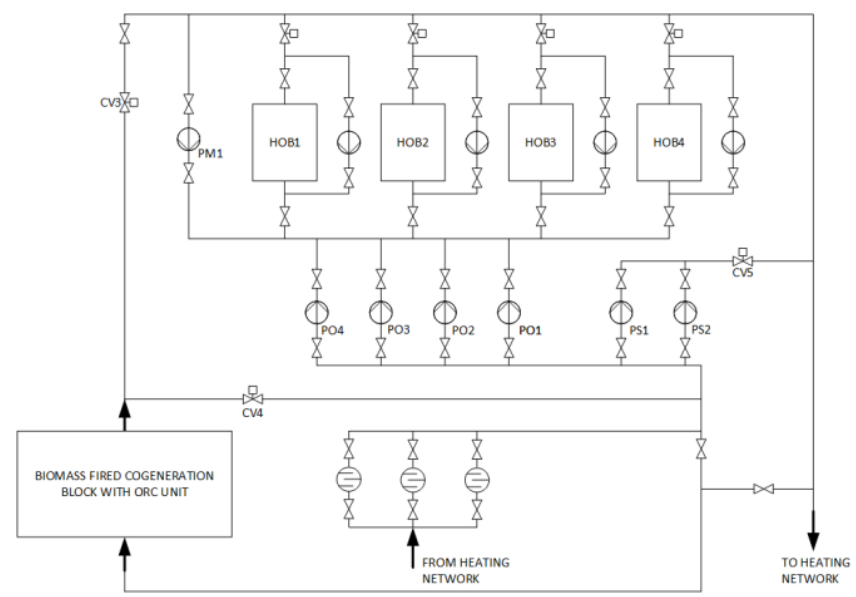

Fig. 1. Schematic process diagram of the CHP plant in K rosno

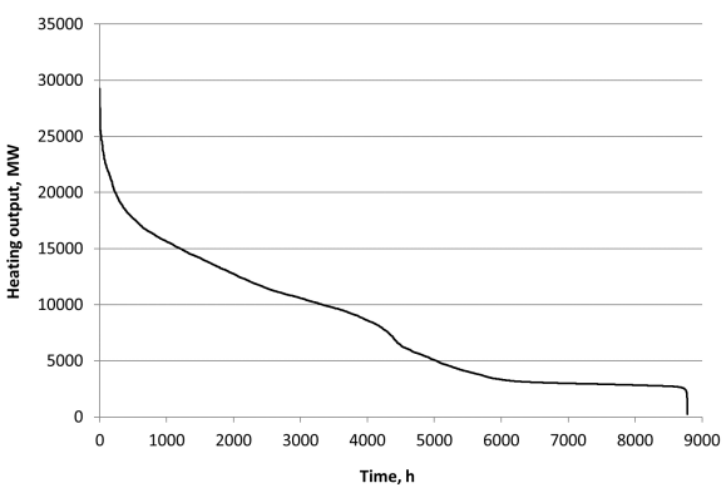

Fig. 2. Heat load duration curve

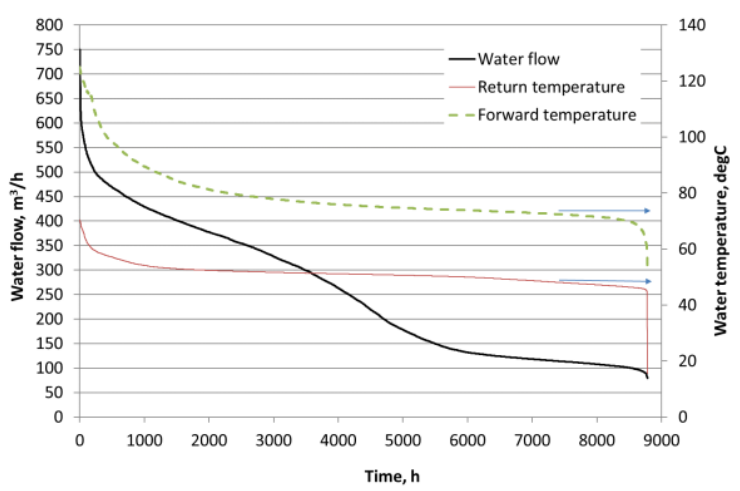

Fig. 3. Water temperature and flow duration curves

Within the heat only block there are 4 WR type forced circulation coal-fired water-tube boilers with mechanical grate (HOB1-HOB4). This is one of the most popular boiler constructions in the Polish heating sector. The nominal heating output of the WR10 boiler is 10 MWth and of the WR4.8 is $4.8 \mathrm{MWth}$. Design thermal efficiency of each boiler is at the level of $83 \%$ (ratio of heat output to fuel LHV chemical energy input). The fuel is hard coal of the lower heating value (average weighted): $\mathrm{LHV}=23.2 \mathrm{MJ} / \mathrm{kg}$.

Technological structure of the biomass-fired ORC block in Krosno has been depicted in Fig. 4.

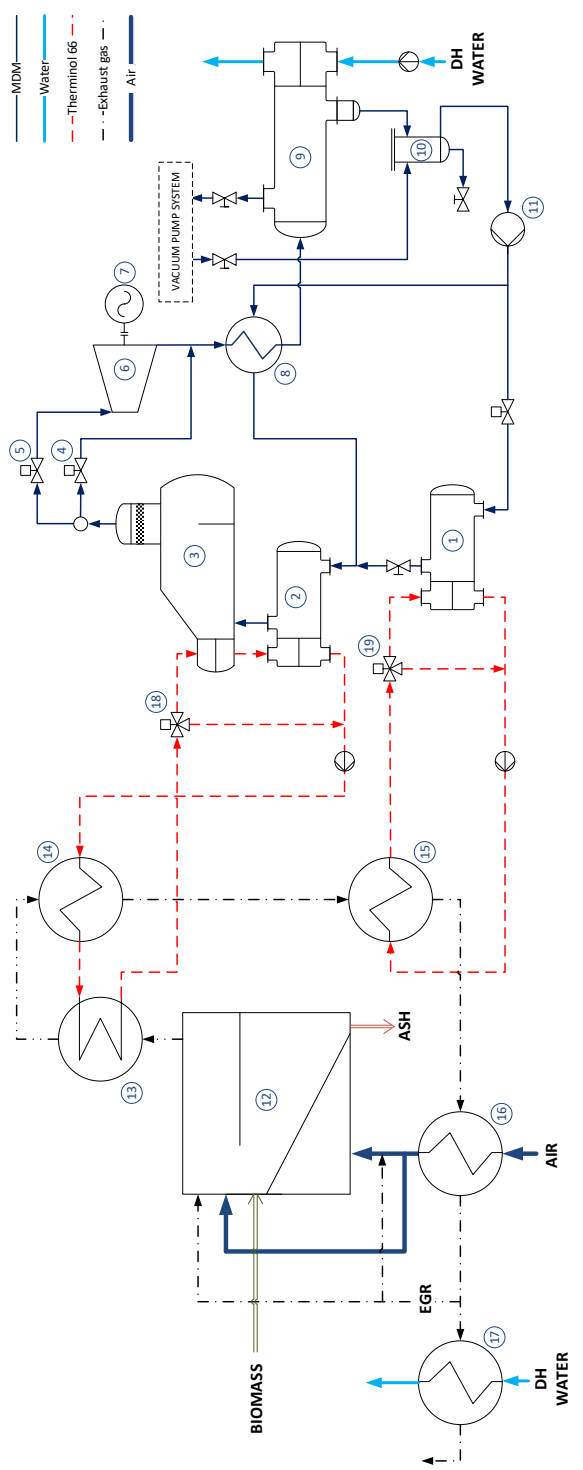

Fig. 4. Process diagram of biomass-fired $O R C$ reference block (legend: 1 - SPLIT heat exchanger/M DM preheater; 2 - M DM heater; 3 - MDM evaporator; 4 turbine by-pass valve; 5 turbine inlet valve; 6 - turbine; 7 - electric generator; 8 working fluid regenerative heat exchanger; 9 - MDM condenser/DH network water heater; 10 - filter; 11 - pump; 12 - biomass combustion furnace; 13 - spiral type thermal oil heater; 14 - high temperature economiser; 15 - low temperature economiser; 16 - recuperator/combustion air heater; 17 - exhaust gas latent heat recovery unit (condensation) 18,19 - thermal oil three-way admission valves; EGR - exhaust has recirculation)

The ORC unit was sized for the base heating load of the district heating network. The rated thermal output of the condenser is $5341 \mathrm{~kW}$ and the maximum output is $5350 \mathrm{~kW}$. The ORC module' generator has the rated electrical power output of $1400 \mathrm{~kW}$. The rated power of the biomass-fired furnace is $8529 \mathrm{~kW}$. The furnace is adjustable in the power range of $30-100 \%$. The rated heat output of the flue gas-thermal oil heat exchangers 
is: $6715 \mathrm{~kW}$. The energy efficiency of the boiler declared by the manufacturer is $85-88 \%$, which has been confirmed by measurements. The fuel delivered into the biomass boiler has variable composition and water content of up to $55 \%$. Its lower heating value is between $8-12 \mathrm{MJ} / \mathrm{kg}$. The quality of fuel varies both seasonally and daily. Thermal oil system consists of two loops: high temperature $\mathrm{HT}\left(310 / 250^{\circ} \mathrm{C}\right)$ and low temperature $\mathrm{LT}$ $\left(250 / 130^{\circ} \mathrm{C}\right)$. The thermal oil transfers heat to the evaporator and the working fluid preheater of the Turboden 14 CHP SPLIT ORC module. The working fluid within the ORC is MDM (Octamethyltrisiloxane). After expansion in the ORC turbine the working fluid goes through the regenerative heat exchanger to the condenser 9 where heat is transferred to the heating network. Operational experiences of this system have been discussed in [12].

\section{Optimisation problem}

The problem in this work is to optimally design new biomass-fired ORC cogeneration block for existing coalfired heating plant. The plant is located in Poland where the system of incentives has been established for cogeneration and renewable energy projects in the form of market oriented Quota Obligation Systems [1]. The ORC unit will be installed at a plant of the fuel chemical energy input higher than $20 \mathrm{MW}$, thus being subject to European $\mathrm{CO}_{2}$ Trading System (ETS). Therefore, another financial support instrument for the investment project is the trade of European Emission Allowances (EUA). Moreover, the electricity is partly used to cover own demand of the company and partly traded on the balancing market at variable prices. The project does not affect the amount and the parameters of the generated network heat.

There have to be decided values of key decision variables to achieve the best value of a selected quality indicator (objective function) under given constraints. These are: load profiles, feedstock characteristics, parameters of district heating water, energy and substance balances, equations of thermodynamic processes, equations of state, stoichiometry of combustion reactions, heat transfer principles, process dynamics, characteristics of equipment, properties and limitations of substances (working fluid, heat transfer oil, combustion gasses), etc. Eventually, the task is:

$$
\begin{array}{cc} 
& \min J\left(x_{1}, x_{2}, \ldots, x_{n}\right) \\
\mathrm{s.t.} & G_{i}\left(x_{1}, x_{2}, \ldots, x_{n}\right)=0 ; i=1,2, . . k \\
& H_{j}\left(x_{1}, x_{2}, \ldots ., x_{n}\right)>0 ; j=1,2, . . m
\end{array}
$$

where $x_{i}$ are independent decision variables.

Traditional economic indices of investment projects, i.e. N et Present V alue (NPV) and Internal Rate of Return (IRR) within given time horizon have been assumed to be al ternative objective functions:

$$
\begin{gathered}
J=N P V \text { or } J=I R R \\
N P V=\sum_{t=1}^{N} \frac{\Delta C F_{t}}{(1+r)^{t}}-C A P E X
\end{gathered}
$$

$$
\sum_{t=1}^{N} \frac{\Delta C F_{t}}{(1+I R R)^{t}}-C A P E X=0
$$

Where: CAPEX - capital expenditures [PLN ]; CF - cash flow [PLN ]; N - project duration (years); r- discounted cash flow rate; $\mathrm{t}$ - year number,

Although many system parameters need to be selected at the design stage [6-9] in this work the number of independent decision variables has been limited to the nominal power of the ORC generator and the volume of TES. The search limits have been set within the range of $200-5000 \mathrm{~kW}$ and $200-5000 \mathrm{~m}^{3}$ for TES volume respectively. Instead of detailed modelling of the thermodynamic cycle the nominal electrical efficiency of the ORC unit has been determined using market data for biomass-fired ORC cogeneration units with MDM as working fluid and $60 / 80^{\circ} \mathrm{C}$ cooling water temperature [15]:

$$
\eta_{\text {el,nom }}=0.0122 \ln \dot{P}_{\text {el,gen,nom }}+0.1004
$$

Total capital expenditures (CAPEX) for biomassfired ORC CHP systems have been assessed using data published by IFC [14]. These data have been fitted with the curve (in EUR/m³):

$$
\text { CAPEX }_{C H P}=5584,4\left(\dot{P}_{\text {el, gen }, \text { nom }}\right)^{-0,266}
$$

In the case of TES the investment cost equation has been elaborated using vendors data (in $\mathrm{PL} \mathrm{N} / \mathrm{m}^{3}$ ):

$$
C A P E X_{T E S}=-1409 \ln V_{T E S}+14797
$$

Although accuracy of this initial model is limited it represents design nonlinear trend curves for ORC systems. The methodology is typical for prescreening of possible solutions and identification of potential location of the optimum. In the region of optimum an additional sensitivity analysis would be required in a real business case.

The most important component of the objective function is the differential annual cash flow $\Delta C F_{t}$ within the operational phase, which results from comparison of cash flows after and before the cogeneration project. It takes into account the incomes resulting from the support mechanisms, thus in Polish conditions it is:

$$
\begin{gathered}
\Delta C F_{t=1 \div N}=\int_{\tau_{0}}^{\tau_{a}}\left[\dot{E}_{e l, \exp } p_{e l, \exp }(\tau)+\dot{E}_{e l, s e l f} s c_{e l}(\tau)+\right. \\
\left.\dot{E}_{e l, g e n} \sum_{s u p} f_{\text {sup }}(\tau)-\dot{m}_{b} s c_{b}-\Delta \dot{m}_{c} s c_{c}\right] d \tau- \\
\Delta m_{e n v, t} s c_{e n v, t}-\Delta T_{t}
\end{gathered}
$$

where: $\dot{E}_{\text {el,exp }}$ - el ectricity exported [kW ]; $p_{\text {el,exp }}(\tau)-$ electricity price at time [PL N/kW h]; $\dot{E}_{\text {el,self }}$ - self consumption of electricity [kW ]; $s c_{e l}(\tau)$ - specific cost of electricity at time $\tau[\mathrm{PLN} / \mathrm{kWh}] ; \dot{E}_{\text {el,gen }}$ - generator power output $[\mathrm{kW}] ; \sum_{\text {sup }} f_{\text {sup }}(\tau)$ - total income from support instruments [PL N/kW h]; $\dot{m}_{b}$ - biomass flow [kg/s], $s c_{b}-$ specific cost of biomass [PLN/kg]; $\Delta \dot{m}_{c}-$ reduction of coal consumption $[\mathrm{kg} / \mathrm{s}] ; s c_{c}$ - specific cost of coal $[\mathrm{PLN} / \mathrm{kg}] ; \Delta m_{\text {env,t }}$ - environmental impact in year $\mathrm{t}[\mathrm{kg}] ; s c_{e n v, t}-$ specific costs due to use of environment [PL N/kg]; $\Delta T_{t}$-change of tax in year $\mathrm{t}$ 
$\Delta m_{e n v, t} s c_{e n v}=\Delta m_{f, i} \zeta_{e n v, j, i} s c_{e n v, j}+$

$\Delta m_{f, i} \zeta_{\mathrm{CO} 2} p_{E U A}(\tau)+\Delta m_{a} s c_{a}$

Where: $\Delta m_{f, i}$ - change of i-th fuel consumption [kg], $\zeta_{\text {env }, j, i}$ - specific emission index of pollutant $j$ from fuel $i$ $[\mathrm{kg} / \mathrm{kg}] ; s c_{e n v, j}$ - specific cost for pollutant $j[\mathrm{PLN} / \mathrm{kg}$; $\zeta_{\mathrm{CO} 2}$ - emission index for $\mathrm{CO}_{2}[\mathrm{~kg} / \mathrm{kg}], p_{E U A}(\tau)-$ specific prices of EUA at time $\tau[P L N / k g]$.

Equation (10) takes into account only key income and cost components. Changes of other financial items after the project, such cost of materials, cost of labour etc. have been assumed to be negligible.

The main equality constraint $G_{i}$ is the overall heat bal ance of the district heating plant:

$$
\sum_{k} \dot{Q}_{d, k} \pm \dot{Q}_{T E S}=\dot{Q}_{D H S}+\dot{Q}_{\text {plant }}
$$

Where: $\dot{Q}_{d, k}$ - heat flux delivered by device k [kW], $\dot{Q}_{T E S}$ - heat flux to/from storage $[\mathrm{kW}] ; \dot{Q}_{D H S}$ - heat delivered to the district heating grid, [kW]; $\dot{Q}_{\text {plant }}$ - heat consumed at the plant [kW ]

It has been assumed that in order to minimize heat losses from TES the initial and final states of charge are the same. This assumption gives the following constraint:

$$
\left.\Delta Q_{T E S}\right|_{0} ^{24}=\sum_{t}\left(Q_{T E S}-Q_{l, T E S}\right)_{t}=0
$$

The state of charge has been calculated assuming no heat storage in connecting pipes and no losses:

$$
\frac{\delta\left(\mathrm{Q}_{\mathrm{TES}}\right)}{\delta \tau}= \pm \dot{Q}_{T E S}
$$

Sales of electricity on bal ancing market result from momentary balance of electric power:

$$
\dot{E}_{e l, e x p}=\dot{E}_{e l, g e n}(1-\alpha)-\dot{E}_{e l, p l a n t}-\sum_{c p} \dot{E}_{e l, c p}(15)
$$

Where $\dot{E}_{e l, c p}$ - self consumption of el ectricity in other consumption points that the plant itself.

Fuel consumption is calculated using efficiency characteristics:

$$
\begin{gathered}
\dot{m}_{c}=\frac{\dot{Q}_{H O B}}{\eta_{H O B} L H V_{C}} \\
\dot{m}_{b}=\frac{\dot{Q}_{O R C}}{\left(\sigma \eta_{e l} \eta_{T O} \eta_{B B}\right) L H V_{b}}
\end{gathered}
$$

Nominal energy efficiency of coal boilers has been determined at $\eta_{\text {HOB,nom }}=0.835$. Nominal efficiency of biomass boiler has been assessed as $\eta_{B B, n o m}=0.854$.

As the annual financial effect of system operation depends on part load characteristics of equipment relevant curves have been developed. Part load energy efficiency curve of coal boilers have been adopted from design documentation of the WR type boilers. It takes the form:

$$
\frac{\eta_{H O B}(\tau)}{\eta_{H O B, \text { nom }}}=\mathrm{a}\left(\frac{\dot{Q}_{\text {HOB }}(\tau)}{\dot{Q}_{H O B, \text { nom }}}\right)^{2}+b\left(\frac{\dot{Q}_{H O B}(\tau)}{\dot{Q}_{H O B, n o m}}\right)
$$

Where $a=-1.1056$ and $b=2.1056$. Part load energy efficiency characteristics of biomass boiler has been developed using long term historical measurement data of the Krosno system in real operational conditions, which are available within the archive of the plant's SCADA. It has been applied in the normalised form:

$$
\frac{\eta_{B B}(\tau)}{\eta_{B B, \text { nom }}}=\mathrm{a}\left(\frac{\dot{Q}_{\text {ORC }}(\tau)}{\dot{Q}_{\text {ORC, nom }}}\right)^{2}+\mathrm{b}\left(\frac{\dot{\dot{Q}}_{\text {ORC }}(\tau)}{\dot{Q}_{\text {ORC, nom }}}\right)+\mathrm{c}
$$

Where $a=-0.1142, b=0.1315$ and $c=0.9828$. Performance characteristics of the ORC unit have been also developed and presented in [13]. These parameters have been normalised and applied in dimensionless form. In the first step, for an assumed nominal heating output of the ORC unit $\dot{Q}_{O R C, n o m}$, momentary heating load $\dot{Q}_{O R C}(\tau)$ and water outlet temperature $t_{w 2}$ the equival ent heating output of the TI 14 ORC unit is calculated:

$$
\dot{Q}_{\text {eqv }}=\left(\frac{\dot{Q}_{\text {ORC }}(\tau)}{\dot{Q}_{\text {ORC,nom }}}\right) \cdot \dot{Q}_{T 14, \text { nom }}
$$

Then the ORC's generator momentary power output is calculated using formula:

$$
\begin{gathered}
\dot{E}_{e l}(\tau)=\frac{\dot{E}_{e l, n o m}}{\dot{E}_{T 14, n o m}}\left[a+b\left(\frac{t_{\text {oil }}(\tau)}{t_{w 2}(\tau)}\right)+c \dot{Q}_{e q v}+\right. \\
\left.d\left(\frac{t_{\text {oil }}(\tau)}{t_{w 2}(\tau)}\right)^{2}+e\left(\frac{t_{\text {oil }}(\tau)}{t_{w 2}(\tau)}\right) \dot{Q}_{e q v}+f\left(\dot{Q}_{\text {eqv }}\right)^{2}\right]
\end{gathered}
$$

Where: $a=-183.3 ; b=87.49 ; c=0.3291 ; d=14.21 ; e=-$ $0.03988 ; f=4.998 \mathrm{e}-06$. Electrical efficiency of the $\mathrm{ORC}$ unit is:

$$
\begin{aligned}
& \eta_{e l}(\tau)=\frac{\eta_{e l, n o m}}{\eta_{T 14, n o m}} \\
& {\left[a+b\left(\frac{t_{\text {oil }}(\tau)}{t_{w 2}(\tau)}\right)+c\left(\frac{t_{\text {oil }}(\tau)}{t_{w 2}(\tau)}\right)^{2}+d \dot{Q}_{e q v}\right]}
\end{aligned}
$$

Where: $a=0.02492 ; b=0.0839 ; c=0.3291 ; d=2.88 \mathrm{e}-06$

[13]. Therminol 66 heat transfer oil temperature at the ORC evaporator inlet is:

$$
\begin{aligned}
& t_{o i l}(\tau)=a+b t_{w 2, i}+c \dot{Q}_{e q v}+d t_{w 2}(\tau) \dot{Q}_{e q v} \\
& +e \dot{Q}_{\text {eqv }}
\end{aligned}
$$

where: $a=155.7 ; b=0.8288 ; c=0.023 ; d=-0.81 e-05$; e=1.95e-07 (Kalina, Świerzewski, 2019).

Inequality constraints result from allowable load range of each heating device $k$ :

$$
\dot{Q}_{k, \min } \leq \dot{Q}_{k} \leq \dot{Q}_{k, \max }
$$

According to measurements, minimum load of the CHP unit has been assumed $0.3 \dot{Q}_{O R C, n o m}$ whereas minimum load of coal boilers is $0.2 \dot{Q}_{\mathrm{HOB}, \text { nom }}$ and the maximum is $1.2 \dot{Q}_{\text {HOB, nom }}$.

The inequality constraint of TES charging and discharging processes is the charging/discharging rate, which results from the water flow rate in connecting pipelines:

$$
\begin{gathered}
\dot{Q}_{T E S, \min } \leq \dot{Q}_{T E S} \leq \dot{Q}_{T E S, \max } \\
w_{\min } \leq w \leq w_{\max }
\end{gathered}
$$


In addition the state of charge should not be higher than the maximum one, which results from the given volume of the storage tank:

$$
Q_{T E S} \leq Q_{T E S, \max }=\mathrm{V}_{\max } \mathrm{c}_{p, w} \cdot \Delta \bar{T}_{w} \cdot \rho_{w}
$$

The annual time of CHP operation results from its availability. Basing on experiences of the $\mathrm{K}$ rosno system, the maximum availability has been assumed at $95 \%$, what gives 8322 hours per year of the ORC unit operation. There have been distinguished two modes of operation: summer and winter [13]. In the case with TES, the winter mode is realised in periods when daily average DHS heating load is in the range:

$$
\overline{\dot{Q}_{\mathrm{DHS}}} \geq \dot{Q}_{\mathrm{ORC}, \max } \cup \overline{\dot{Q}_{\mathrm{DHS}}}<\dot{Q}_{\mathrm{ORC}, \min }
$$

In this mode the TES loading and unloading is controlled to minimize coal consumption:

$$
m_{\mathrm{c}} L H V_{c}=\int_{\tau=0}^{\tau=24}\left(\frac{\dot{Q}_{\mathrm{HOB}}}{\eta_{\mathrm{HOB}}}\right) \mathrm{d} \tau \rightarrow \min
$$

The summer mode is realised in periods when daily average DHS heating output is in the range:

$$
\overline{\dot{Q}_{\mathrm{DHS}}}<\dot{Q}_{\mathrm{ORC}, \max } \cap{\overline{\dot{Q}_{\mathrm{DHS}}}} \geq \dot{Q}_{\mathrm{ORC}, \min }
$$

Then the local objective function is income from the sale of electricity on balancing market:

$$
\int_{\tau=0}^{\tau=24} \dot{E}_{\text {el,exp }} p_{\text {el,exp }}(\tau) \mathrm{d} \tau \rightarrow \max
$$

The task can be classified as a M ixed Integer $\mathrm{N}$ on Linear Programming (MINLP) problem, in which the constrains vary with time and the set of decision variables may be discontinuous. There can also occur local extremes, which have been identified by searching the area of trial solutions.

\section{Results and discussion}

In order to examine the influence of design assumptions on financial performance of projects the optimisation task has been solved for K rosno DHS by searching the area of acceptable solutions. For a given trial size of the ORC system the simulation of annual operation was performed. Then the results of annual mass and energy balance have been used for financial calculation within 15 years of project economic lifetime. Prices have been valid for Polish conditions at the beginning of the year 2019. Coal price is $14.50 \mathrm{PLN} / \mathrm{G}$, biomass price is $18.22 \mathrm{PLN} / \mathrm{G}$, EUA price is 103.20 $\mathrm{PLN} / \mathrm{Mg}$, price of certificate of electricity origin from RES is $130.0 \mathrm{PLN} / \mathrm{MWh}$, electricity price for own consumption is $370 \mathrm{PLN} / \mathrm{MWh}$, discounting cash flow rate is $r=0.05$, possible subsidies for investment project are at the level of 0.3CA PEX.

Figures 5 and 6 depict operation of ORC units of different size and HOB s within the DHS in the case there is no TES. The annual operating time of larger ORC systems is shorter due to the fact that their minimum permissible heating load is higher than the load of the grid.

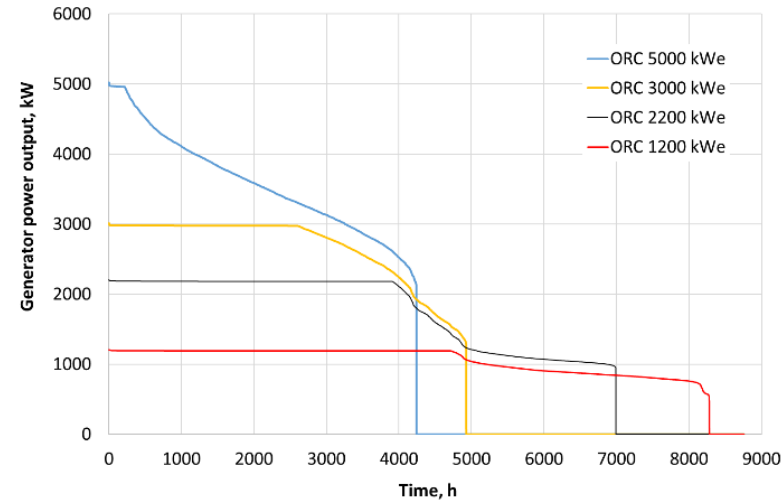

Fig. 5. ORC power duration curve

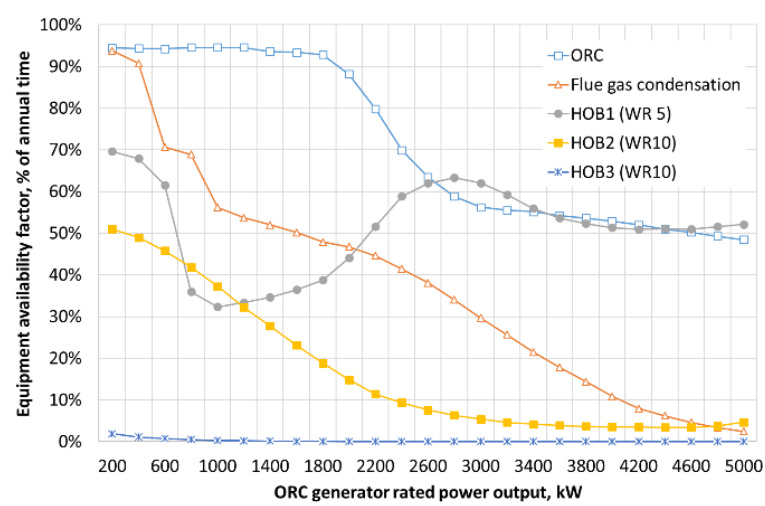

Fig. 6. A nnual time of equipment operation

NPV and IRR of the project under different assumptions on financing have been depicted in Fig. 7 to 10 for the system without and with TES respectively. Adding TES to the system moves optimum size of the ORC unit towards larger values. However, under current economic conditions the TES only slightly changes values of objective functions N PV and IRR.

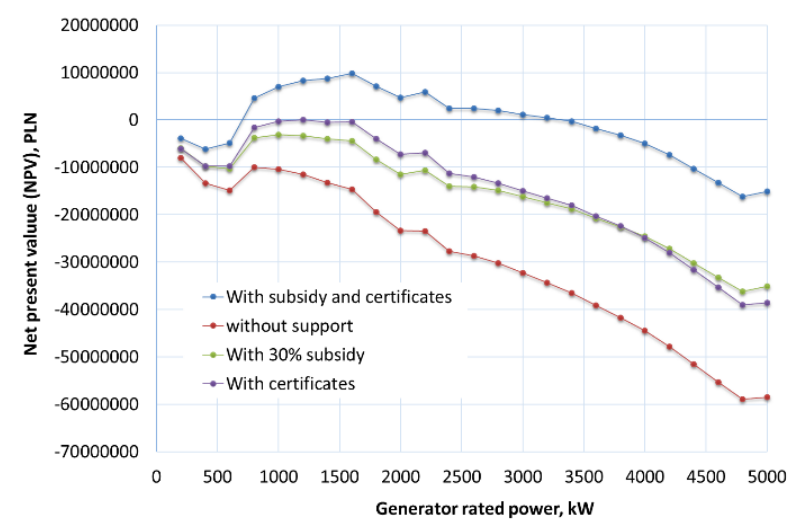

Fig. 7. NPV under different financing options (system without TES) 


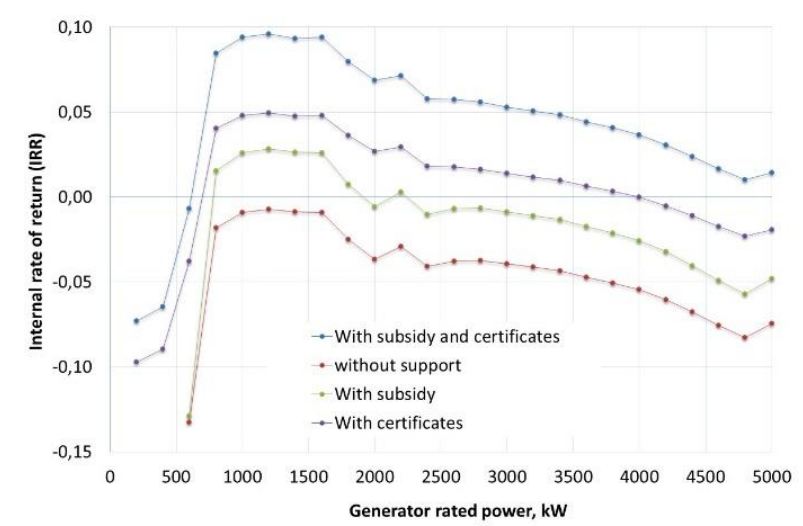

Fig. 8. IRR under different financing options (system without TES)

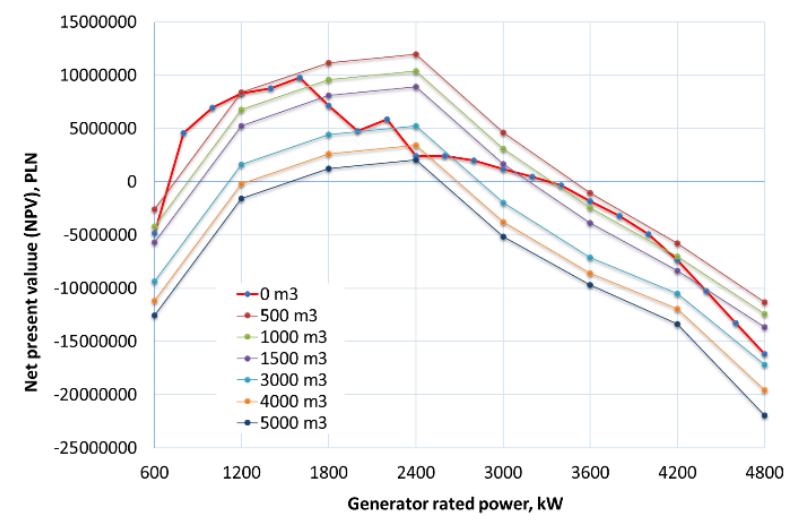

Fig. 9. IRR under different financing options (system with TES)

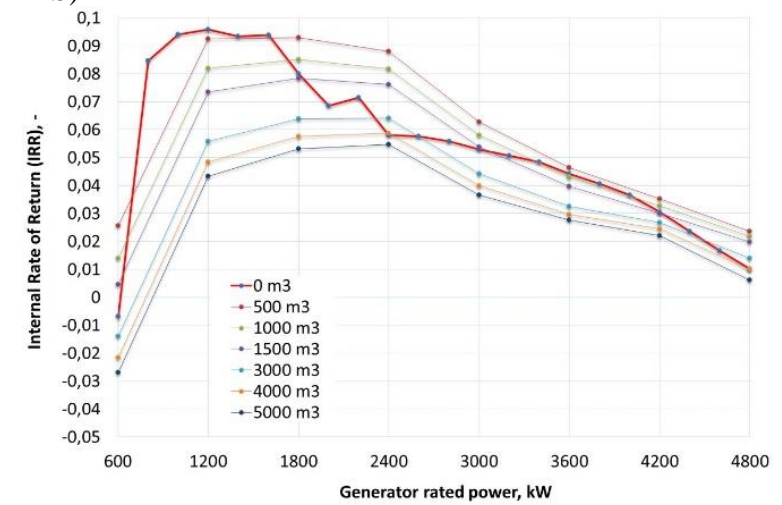

Fig. 10. IRR under different financing options (system with TES)

Results revealed that although the ORC technology has been intensively developed for last two decades biomass-fired cogeneration projects are still heavily dependent on financial support. Without support profitability of the project can't be reached. Figure 11 depicts structure of income of the best case without TES. It can be noted at current prices the support mechanism, which mostly influences the profitability is emission trading system. As this mechanism is marked based and connected with significant uncertainty and risk it does not encourage investment projects to be undertaken.

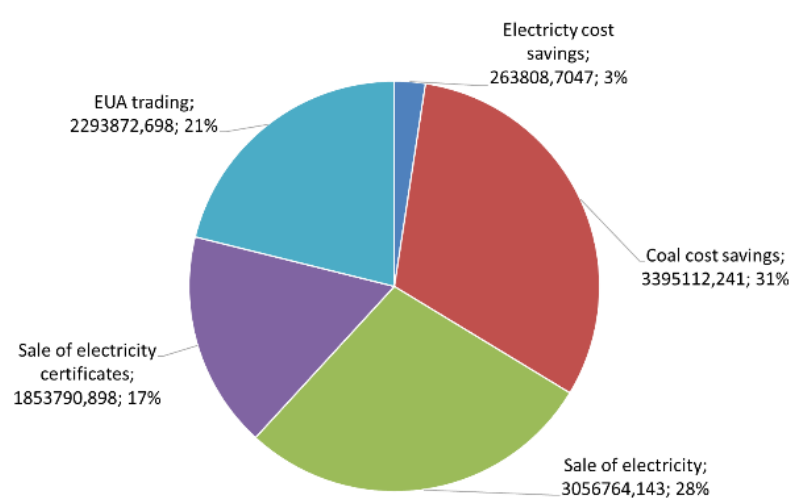

Fig. 11. Income structure for the best system of $2400 \mathrm{~kW}$ power output with $500 \mathrm{~m}^{3}$ TES

After taking into consideration current conditions of electricity and EUA prices there had been assumed within the next simulation price variability paths. For $\mathrm{CO}_{2}$ several forecasts have been taken into account and average value has been estimated. In the case of electricity the price path has been developed on the basis of the report provided by the Jagiellonian Institute [16]. Both paths are depicted in Fig. 12.

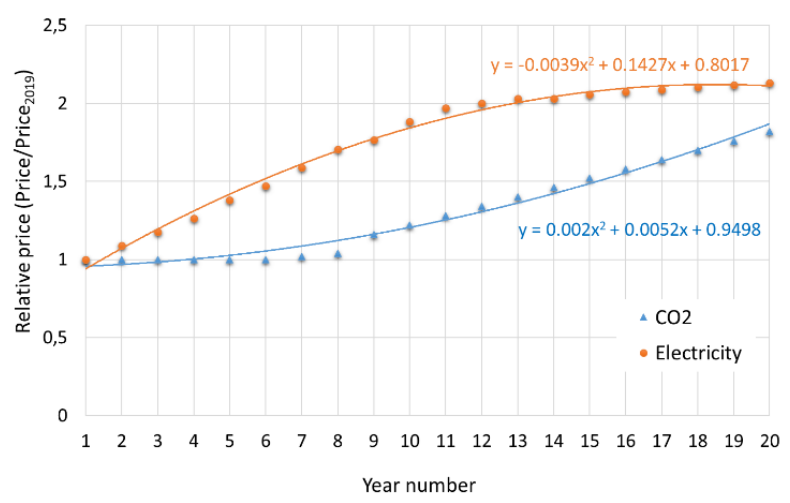

Fig. 12. Adopted price paths for electricity and $\mathrm{CO}_{2}$ (year 1 is 2019)

Figures 13 and 14 depict NPV and IRR for different ORC generator rated power output of the system without heat storage. It can be concluded that qualitative results are the same for both studies. However, in the case of variable prices the NPV curve gets flattened. This is because losses due to shorter annual time of operation in the case of larger generators are compensated by higher incomes. Quantitatively the increase of electricity and EUA prices significantly improves financial performance of the project. Discounted payback period (DBP) for the optimal system in the case of variable electricity prices shortens from 12 to around 8.5 years. 


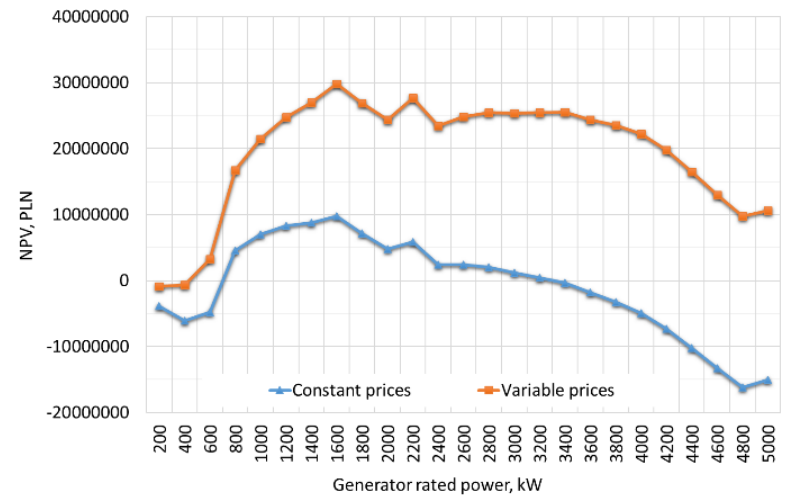

Fig. 13. NPV under constant (2019) and variable prices of electricity and EUA (system without TES)

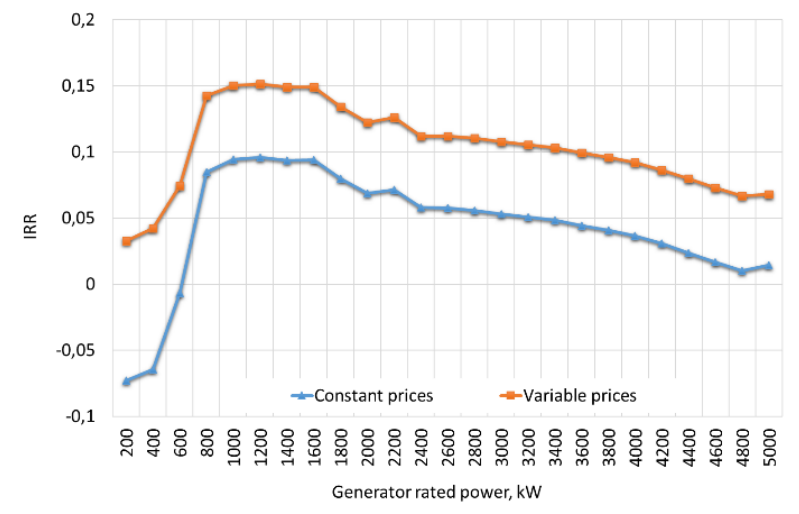

Fig. 14. IRR of projects under constant (2019) and variable prices of electricity and EUA (system without TES)

Results for ORC cogeneration system with $500 \mathrm{~m}^{3}$ TES are depicted in Fig. 15 and 16. In the case of NPV the shape of curve has changed significantly strongly indicating the location of the optimal generator rated power, which is the same as in the case of constant prices. In the case of IRR the optimal value has slightly move towards higher values.

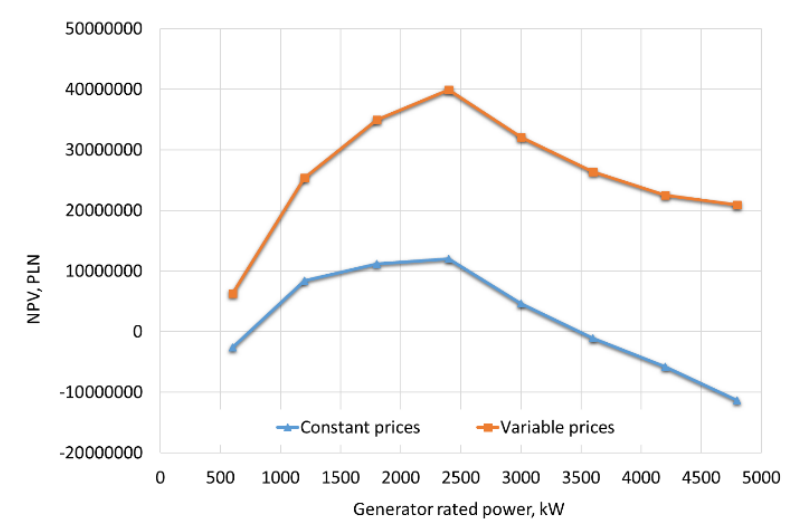

Fig. 15. NPV under constant (2019) and variable prices of electricity and EUA (system with $500 \mathrm{~m}^{3}$ TES)

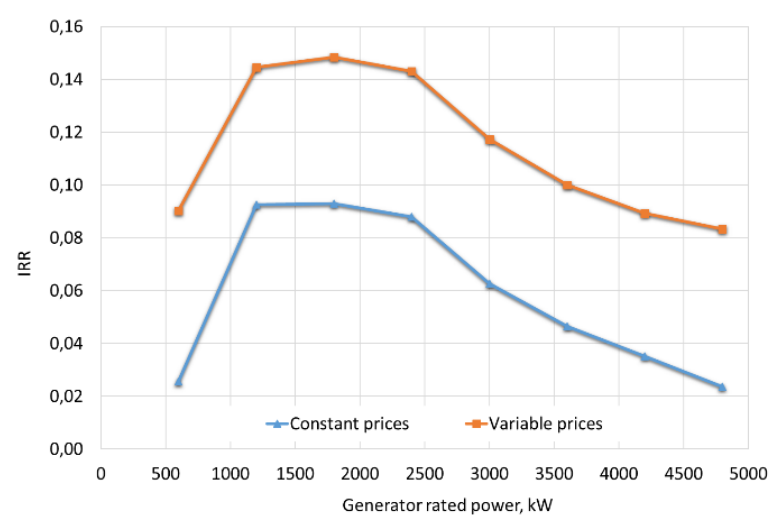

Fig. 16. IRR of projects under constant (2019) and variable prices of electricity and EUA (system with $500 \mathrm{~m}^{3} \mathrm{TES}$ )

\section{Conclusions}

The problem of optimal sizing and selection of technological structure of biomass-fired ORC cogeneration system for backfitting of fossil fuel-fired district heating plant has been presented in the paper. In Polish conditions, there are many DHS where such projects could be potentially executed. Results of this study revealed that feasible projects are possible if the ORC system is optimally sized for given site conditions. On the other hand profitability of investment is still relatively low and dependent on unstable market conditions and financial support. Discounted payback period for a feasible project can be expected within the range of 12 years. This value doesn't suggest significant investments will be triggered in the near future in the field of biomass fired cogeneration based on the ORC technology. Adding thermal energy storage and selling electricity on balancing market have improved financial performance only to a small extent.

An important conclusion is that economic optima are relatively flat and the range of system sizes, for which the value of objective function is close to the optimum is quite wide. Recommended solutions are the ones with relatively long annual time of operation. The analysis proved that sizing of ORC cogeneration unit should aim at covering base heating load of the district heating network. In case of the Krosno project the size of the implemented ORC system appeared to be close to the optimum.

This work was carried out in the project IntBioCHP titled: System integration of biomass fired cogeneration plants. The project is financed by German Federal Ministry of Education and Research and Polish Ministry of Science and Higher Education within the framework of the Polish - German Sustainability Research Programme STAIR.

\section{References}

1. Kalina, J.: Equipment sizing in a coal-fired municipal heating plant modernisation project with support for renewable energy and cogeneration technologies. En. Conv. and Man., Vol. 86 (2014), p. 1050-1058. 
2. Tartière T.: ORC Market: A World Overview. Web project available at http://orc-worldmap.org/analysis.html

3. Tańczuk, M., Ulbrich, R.: Implementation of a biomass-fired co-generation plant supplied with an ORC (Organic Rankine Cycle) as a heat source for small scale heat distribution system - A comparative analysis under Polish and German conditions. Energy, Vol. 62 (2013), p. 132-141.

4. Franco, A., Bellina F.: Methods for optimized design and management of CHP systems for district heating networks (DHN). En. Conv. and Man., Vol. 172 (2018), p. 21-31.

5. Duvia, A., Guercio, A., Rossi, C.: Technical and economic aspects of biomass fuelled CHP plants based on ORC turbogenerators feeding existing district heating networks. Proceedings of the 17th European Biomass Conference, Hamburg, Germany, June. 2009, p. 2030-2037.

6. Elsido, C., Mian, A., Martelli, E., A systematic methodology for techno-economic optimization of Organic Rankine Cycles. Energy Proceedia, Vol. 129 (2017), p. 26-33.

7. Martelli, E., Federico Capra, F., Consonni S.: Numerical optimization of Combined Heat and Power Organic Rankine Cycles - Part A: Design optimization. Energy, Vol. 90 (2015), p. 310-328.

8. Capra, F., Martelli, E.: Numerical optimization of combined heat and power Organic Rankine Cycles Part B: Simultaneous design \& part-load optimization. Energy. Vol. 90 (2015), p. 329-343.

9. Taljan, G., Verbic, G., Pantos, M., Sakulin, M., Fickert, L.: Optimal sizing of biomass-fired Organic Rankine Cycle CHP system with heat storage. Energy, Vol. 41 (2012), p. 29-38.

10. Baños, R., Manzano-Agugliaro, F., Montoya, F., G., Gil, C., Alcayde, A., Gómez, J.: Optimization methods applied to renewable and sustainable energy: A review. Ren. and Sust. En. Rev., Vol. 15, (2011), p. 1753-1766.

11. Østergaard, P., A.: Reviewing optimisation criteria for energy systems analyses of renewable energy integration. Energy, Vol. 34 (2009), p. 1236-1245.

12. Kalina, J., Świerzewski, M., Strzałka, R.: Operational experiences of municipal heating plants with biomass-fired ORC cogeneration units. En. Conv. and Man., Vol. 181 (2019), p. 544-561.

13. Kalina, J., Świerzewski M.: Identification of ORC unit operation in biomass-fired cogeneration system. Ren. En.. Vol. 142 (2019), p. 400-414.

14. International Finance Corporation (IFC) in partnership with Austrian Federal of Ministry of Finance, 2017, Converting Biomass to Energy - a Guide for Developers and Investors. Washington, D.C. June 2017. ifc.org

15. Turboden srl. ORC standard units. Datasheet. www.turboden.com.

16. Schnell Ch., Roszkowski M.: Trwały wzrost cen energii zmieni dopiero modyfikacja polskiego miksu energetycznego. Czy stać nas na marnowanie czasu ? Report of the Jagiellonian Institute: Ceny energii. Warsaw,

October
http:/jagiellonski.pl/files/other/2018.10_Instytut_Jag ielloYski_-Ceny_energii_ANALIZA.pdf. 